\title{
Performance analysis of surface reducing gear of rod driven screw pump with involute gearing and Novikov gearing
}

\author{
Kh. N. Yagafarova \\ Ufa State Petroleum Technological University, \\ Branch of the University in the City of Oktyabrsky, Russian \\ Federation \\ Yagafarova-kh@mail.ru
}

\author{
R. A. Teregulov \\ Ufa State Petroleum Technological University, \\ Branch of the University in the City of Oktyabrsky, Russian Federation \\ Yagafarova-kh@mail.ru
}

\begin{abstract}
The given article demonstrates a tooth mesh modification of a surface reducing gear of a rod driven screw pump used for oil production. The Novikov gearing for reducing gear transmission has a set of advantages over the involute gearing being applied at present and is proposed to be used instead. The authors assume that the stated advantages will have a positive impact on motor operation as a whole and will be made use of in oilfield engineering.
\end{abstract}

Key words - rod driven screw pump, motor, reducing gear, tooth gear, involute, Novikov gearing, stress

\section{INTRODUCTION}

Since 1991 the submersible screw pumps with surface motors started to be applied in different regions of Russia for high-viscosity oils production and low-debit wells operation, which was caused by the reduction of oil well debits [1]. The exploitation of a surface motor enables to use expensive equipment [2]. The motors of rod driven screw pumps have different versions, for example, belt gearing and chain drive gearing as well as reducing gear unit can be applied as driving mechanisms. The most frequently, an angular belting singlestage motor is used due to the fact that this type of motor is less expensive and has low mass properties; moreover, the columns change motor sheaves with the aim to control the speed rate. However, in case of a belt tear or oil production regulation it is necessary to terminate the well operation, which is highly undesirable. Consequently, a high-priority task in the process of producing tight high-viscosity oils is the increase of mean time between overhauls of a screw pump motor.

\section{II.MAIN PART}

Motors with reducing gear units are less accepted due to their high price, however, their operational capacity is higher than the one of the belt or chain driving. Figure 1 demonstrates a unit of the rod driven submersible screw pumps, whose stator interlocks solidly with the tubing string and the screw - with the string of rods situated inside a tubing string $[3,5]$. The lower part of the pump contains a reversing valve preventing string reverse rotation in case of emergency, e.g. engine turning off or surface motor breakdown. Ground equipment session consists of an electric motor, double reducing gear, three-way blowout preventer and a string head. A pump screw produces rotary motions due to the rotation of a rods string placed inside a tubing string, which is driven by a surface motor. 


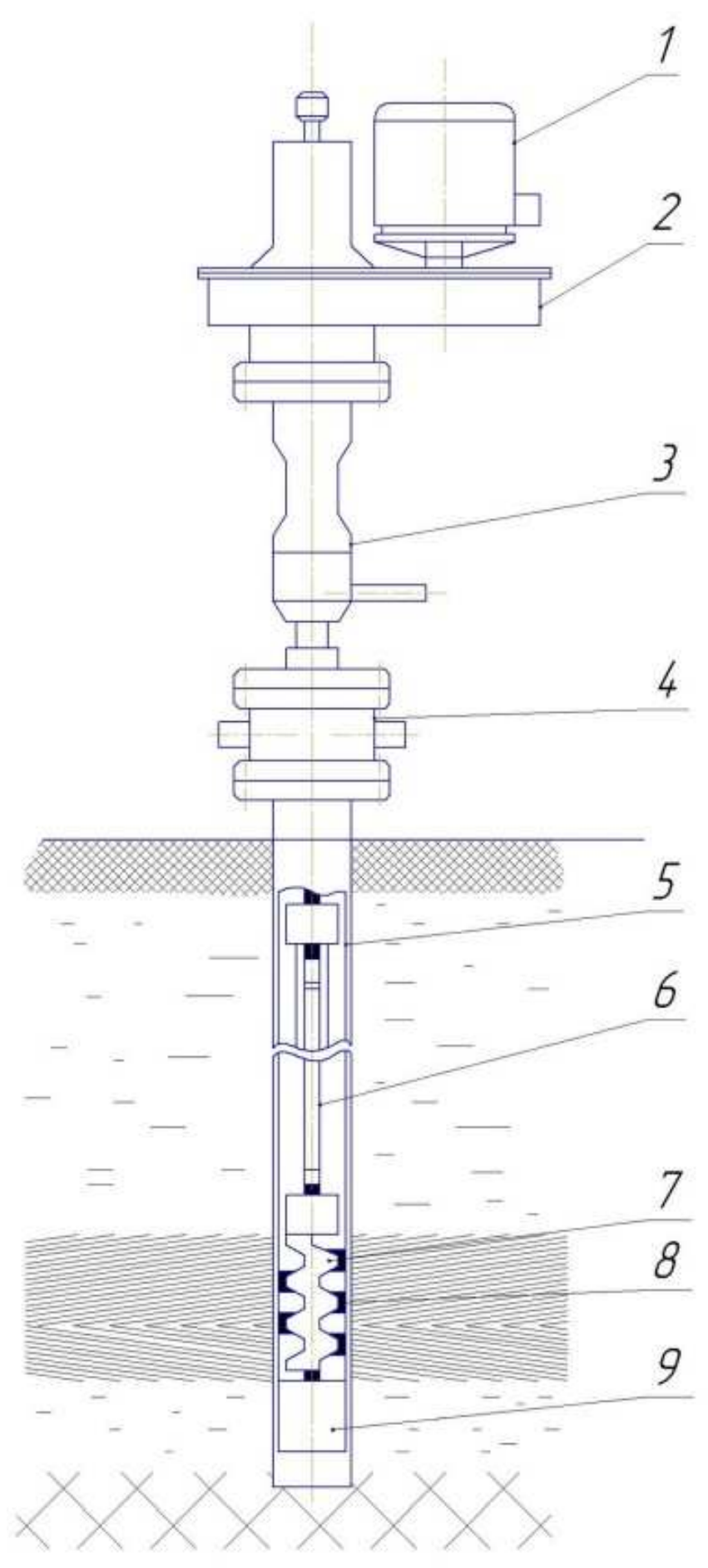

Fig. 1. Rod driven screw pump developed in USPTU: 1 - electric motor; 2 reducing gear; 3 - three-way blowout preventer; 4 - string head; 5 - tubing strings; 6 - rods string; 7 - pump rotor; 8 - pump stator; 9 - reversing valve.

A motor of a screw pump with a reducing gear unit and involute gearing is widely used nowadays on account of being more reliable and durable in comparison with the other surface motors. However, this type of a motor has disadvantages being the following:
1) insufficient load capability of involute teeth of motor transmission;

2) sensitivity to misalignment of reducing gear's shaft axis caused by the linear contact of involute gearing.

These disadvantages are greatly diminished in the gearing developed by a Soviet scientist and developer, M.L. Novikov in 1954 [4, 7]. Involute profiles of the gearing wheels' teeth are exchanged with circular profiles in Novikov gears. A contact pattern in this type of teeth engagement is transmitted along the teeth rather than along the involute profile, at which point a contact angle and movement speed stay constant. To keep the rotation integrity the Novikov's gear engagement are implemented via helical engagements.

The tooth contact in Novikov's gear is implemented in a point and not along a line as with involute transmissions without taking into account deformation and run-in. However, a small difference of the concave and convex tooth curvature radiuses as well as long radiuses of helical teeth curvature in the normal plane leads to the situation when the point contact changes into the spot contact under pressure. As a consequence, the contact stresses are considerably reduced because the contact of profiles with small differences of curvature radiuses is at work instead of convex involute profiles. Tooth's active surfaces are the tubular circular arc tooth surfaces; as a consequence, Novikov's gear can be called a circular arc one [6].

Novikov's gear has the increased contact strength. In contrast to a similar with regards to the size and material $(\mathrm{HB} \leq 350)$ involute helical tooth gear, teeth hardening is larger by $1.5-1.7$ times. This is primarily due to the expansion of tooth contact area as well as the increase of loading capacity of the oil-film wedge between the teeth. Favourable conditions for oiling lead to the rise of efficiency coefficient and decrease of teeth wear.

Disadvantages of Novikov's gear are as follows: hypersensitivity to the axle spacing alteration, a comparatively complex tool's original profile and a certain decrease of bending resistance in comparison with an involute profile [8].

Nowadays, there are two versions of spur Novikov gearings:

- with one line engagement (OLE);

- with two lines engagement (DLE).

Application of Novikov's gear started with OLE and nowadays gears with DLE and with the original profile as envisaged in GOST (State Standard) 15023-76 are used. It is justified economically and practically because different tools (two original profiles) need to be used for cutting gear and wheel with OLE due to the fact that the profiles of gear and wheel teeth are different. Gear teeth with DLE are obtained with one tool (one original profile). Moreover, these gears possess the increased contact and bending resistance, which has an immediate impact on mass and dimensional characteristics of the surface reducing gear. A profile with regards to GOST (State Standard) 15023-76 is used with the gears having the following characteristics: hardness of $\mathrm{HB}$ $\leq 320$, engagement module of $m \leq 16 \mathrm{~mm}$ and radial velocity of 
$\mathrm{V} \leq 20 \mathrm{~m} / \mathrm{s}$, which assumes the application of Novikov's gear with a gear motor in a power driven reducing gear [9].

According to GOST (State Standard) 14744-72, one of the major geometric characteristics of spur gear is axle spacing, and the decrease of this parameter is the major characteristic in case of downsizing of a power driven reducing gear as a whole. Below there is a formula (1) for the calculation of axle spacing of spur gears [6]:

$$
a_{w}^{*}=k_{a}(u+1)\left[\frac{T_{1} k_{H \beta} k_{A} 10^{3}}{\Psi_{b a}\left(\sigma_{H}\right)^{2} u}\right]^{1 / 3}
$$

where $\mathrm{T}_{1}$ is a gear wheel torque;

$k_{\mathrm{a}}=43 \mathrm{MPa}$ for helical gears;

$\Psi_{\text {ba }}$ is a coefficient of a face width with relation to axle spacing;

$k_{\mathrm{H} \beta}$ is a coefficient taking into account the imbalance of the load over a gear face;

$k_{\mathrm{A}}$ is a coefficient of external dynamic stress

$u$ is gearing ratio;

$\sigma_{\mathrm{H}}$ is working contact stress.

As is seen from the formula (1), axle spacing is inversely proportional to the working contact stress, thus, axle spacing reduction with the lossless teeth's contact and bending resistance is possible under the conditions of heavy operation of the power driven reducing gear of a screw pump.

Point (theoretical) contact makes Novikov's gears less sensitive to misalignment than the gears with linear contact. On the other hand, they are more sensitive to the axle spacing alteration. Therefore, the major criterion of performance and Novikov's gears calculation is contact and bending stress durability.

Novikov's gears calculation for bending resistance is made according to the formula (2):

$$
\sigma_{\mathrm{F}}=\mathrm{Y}_{\mathrm{F}} \mathrm{Y}_{\beta} \mathrm{Y}_{\mathrm{k}}\left(\frac{2 \cdot 10^{3} \mathrm{~T}_{1}}{\mathrm{~m}^{3} \mathrm{z}_{1}} \frac{\mathrm{K}_{\mathrm{Fv}} \mathrm{K}_{\mathrm{F} \alpha}}{\mathrm{K}_{\varepsilon}}\right) \leq\left(\sigma_{\mathrm{F}}\right)
$$

where $\mathrm{T}_{1}$ is a gear wheel torque;

$\mathrm{m}$ is a normal module;

$\mathrm{z}$ is the number of gear teeth;

$\mathrm{Y}_{\mathrm{F}}$ is a teeth shape coefficient;

$\mathrm{Y}_{\beta}$ is an angle of advance coefficient;

$Y_{k}$ is a coefficient of voltage change;

$\mathrm{K}_{\mathrm{F} \alpha}$ is a coefficient of load imbalance between a head and leg of teeth;

$\mathrm{K}_{\mathrm{Fv}}$ is a dynamic load coefficient.

Tooth contact conditions in Novikov's gears differ fundamentally from Hertzian contact conditions. The size of contact area here are proportional to teeth size and contact stresses approximate to the bearing stresses (specific pressures). Thus, the contact stress calculation of Novikov's gears as well as of involute gears is made by Hertz formula (3) for cylinders pressure, however, with some changes characteristic for Novikov's gear:

$$
\sigma_{\mathrm{H}}=\mathrm{Z}_{\mathrm{M}} \mathrm{Z}_{\beta} \mathrm{Z}_{\mathrm{k}}\left(\frac{2 \cdot 10^{3} \mathrm{~T}_{1}}{\mathrm{~d}_{1}^{2} \mathrm{~m}} \frac{\mathrm{K}_{\mathrm{H} v} \mathrm{~K}_{\mathrm{H} \alpha}}{\mathrm{K}_{\varepsilon}} \frac{\mathrm{u}+1}{\mathrm{u}}\right)^{1 / 2} \leq\left(\sigma_{\mathrm{H}}\right)
$$

where $\mathrm{T}_{1}$ is a gear wheel torque;

$\mathrm{m}$ is a normal module;

$\mathrm{Z}_{\mathrm{M}}$ is a coefficient of wheels material stress-strain properties;

$\mathrm{Z}_{\mathrm{B}}$ is a coefficient accounting for the mating surfaces form;

$\mathrm{Z}_{\mathrm{k}}$ is a coefficient accounting for the length of conventional contact line along a tooth height;

$\mathrm{K}_{\mathrm{H} \alpha}$ is a coefficient of load imbalance between a head and leg of teeth;

$\mathrm{K}_{\mathrm{H} v}$ is a dynamic load coefficient;

$\mathrm{K}_{\varepsilon}$ is a coefficient of load distribution over contact areas used for contact and bending stress calculation.

The conditional Hertz formula (2) shows that the contact stress with Novikov's gear with the constant diameter (d) depends on the module $(\mathrm{m})$ and not on the number of teeth $(\mathrm{z})$ in contrast to the involute gears.

For having a visual presentation of the effective application of Novikov's gear in reducing gears of rod driven screw pumps we will compare it with involute gear. For this purpose let us calculate the main characteristics of involute gears and Novikov's gears $[4,7]$. When calculating the main characteristics of reducing gears let us apply the existing procedure of calculating gearings [12]. The calculation data are introduced in Table 1.

TABLE I. COMPARISON OF CHARACTERISTICS OF REDUCING GEAR WITH INVOLUTE GEAR AND NOVIKOV'S GEAR

\begin{tabular}{|c|c|c|}
\hline $\begin{array}{c}\text { Reducing gear } \\
\text { characteristics }\end{array}$ & Involute gear & $\begin{array}{c}\text { Novikov's } \\
\text { gear }\end{array}$ \\
\hline $\mathrm{N} 1, \mathrm{~kW}$ & \multicolumn{2}{|c|}{7.5} \\
\hline $\mathrm{N} 2, \mathrm{~kW}$ & 6.75 & 7.06 \\
\hline $\mathrm{M} 1, \mathrm{Nm}$ & 43.02 & 44.98 \\
\hline $\mathrm{M} 2, \mathrm{Nm}$ & \multicolumn{2}{|c|}{142.5} \\
\hline $\mathrm{n} 1, \mathrm{r} / \mathrm{min}$ & 142.5 \\
\hline $\mathrm{n} 2, \mathrm{r} / \mathrm{min}$ & 0.9 & 0.941 \\
\hline ngen & 275 & 205 \\
\hline 6H, MPa & 122 & 90 \\
\hline $6 \mathrm{~F}, \mathrm{MPa}$ &
\end{tabular}

The table contains data on contact and bending stresses occurring in gearing of the first stage of a reducing gear both with Novikov's and involute gearing which set Novikov's gears apart. It is obvious that loading capacity of Novikov's gear is higher than the one of involute gearing [11, 12]. 


\section{CONCLUSION}

Novikov's gears are being more frequently implemented in various manufacturing sectors due to a set of positive characteristics, primarily, the increased loading capacity. Constructors are studying high frequency gearing modifications as well as gear transmissions with highly rigid teeth driving flanks. In Russia, Novikov's transmissions are standardized. Presently, industry standard for the original profile of rigid transmissions has been developed and maintained. Transmissions with Novikov's gearing have been used in Oil and Gas Engineering for a rather prolonged period, specifically, in motor driven reducing gears TS2NSH, TS3NSH of pumping units. Calculation outcomes and their comparative analysis show that Novikov's gearing is more preferable than involute gearing due to the fact that under the situation of similar initial conditions Novikov's gearing significantly increases power efficiency (ngen) and decrease the specified contact stresses $(\sigma \mathrm{H})$ and the stress on bending $(6 \mathrm{~F})$.

\section{References}

[1] A. R. Brot, B.Z. Sutanov, R. M. Idiyatullin and S. E. Matyas “ Testing of surface-driven screw pumps," Oil industry, Vol. 7, pp. 36-38, 1992.

[2] M. Ya. Khabibullin, R. I. Suleimanov, D. I. Sidorkin and I. G. Arslanov, "Parameters of Damping of Vibrations of Tubing String in the Operation of Bottomhole Pulse Devices," Chem Petrol Eng, vol. 53, pp. 378-384, 2017. https://doi.org/10.1007/s10556-017-0350-6

[3] N.Y. Golovina, L.G. Akhmetov, A.N. Vikharev and I.G. Arslanov, "Analysis on compressor blading conditions of helicopter's gas-Turbine engine working in polluted environment," International Journal of Applied Engineering Research, vol. 12, pp. 293-296, 2017.

[4] V.V. Mukhametshin, "Efficiency estimation of nanotechnologies applied in constructed wells to accelerate field development," (in Russian), Nanotechnologies in Construction, vol. 10, no. 1, 2018, pp. 113-131. DOI: $10.15828 / 2075-8545-2018-10-1-113-131$

[5] A.F. Kirichenko, "Experimental investigation of tooth contact conditions in Novikov gear engagements," RUSS. ENGNG. J., vol. 60, issue 12, pp. 8-10, 1980.

[6] R.R. Shangareev, "Relevance of assessment science research concerning occupational hazards of drilling operations," Ecology, Environment and Conservation Paper, vol. 21, pp. 175-180, 2015.

[7] Y. Qi, "Effects of structure parameters on the vibration behaviors of reducing box with two-stage split-flow Novikov gears of double circular arc tooth profiles", Journal of the University of Petroleum, China (Natural Science Edition), vol. 22, issue 6, 1998, pp. 68-70

[8] K.S. Lin, K. Y. Chan, J.J. Lee, "Kinematic error analysis and tolerance allocation of cycloidal gear reducers", Mechanism and Machine Theory, vol. 124, pp. 73-91, 2018.

[9] X. Zhou, L. Huang and H. Zhang, "The influence of bearing stiffness and gear helix angle on the vibration noise of reducer", Acta Technica CSAV (Ceskoslovensk Akademie Ved), vol. 62, issue 1, pp. 301-311, 2017.

[10] S.T. Bai, "Lubrication of double-arc Novikov gear reducer for pumping units“, OIL FIELD EQUIPMENT, vol. 16, issue 1, pp. 62-64, 1987.

[11] D. Michalopoulos, N. Aspragathos and A.D. Dimarogonas, "Fatigue damage of gear teeth in speed reducers moving heavy rotors", TRANS. ASME J. VIB. ACOUST. STRESS \& RELIAB. DES, Vol. 109, issue 2pp. 196-200, 1987,

[12] I.A. Krol, A.N. Aronzon, "The method of reliability estimation for a mechanism containing electric drive connected to gear reducer", Elektrotekhnika, Issue 8, pp. 26-29, 2004.

[13] Y.L. Jin, W.D. He, L.X. Li and J.Y. Ding, "Tooth profile optimization and kinematic simulation of double crank ring-plate-type pin-cycloidal gear planetary drive", Dongbei Daxue Xuebao, Journal of Northeastern University, vol. 26, issue 5, pp. 481-483, 2005. 